\title{
Quality Control of Gamma Irradiated Dwarf Mallow (Malva neglecta Wallr.) Based on Color, Organic Acids, Total Phenolics and Antioxidant Parameters
}

\author{
José Pinela 1,2, Lillian Barros ${ }^{1}$, Amilcar L. Antonio 1,3 , Ana Maria Carvalho ${ }^{1}$, \\ M. Beatriz P. P. Oliveira ${ }^{2}$ and Isabel C. F. R. Ferreira ${ }^{1, *}$ \\ 1 Mountain Research Centre (CIMO), ESA, Polytechnic Institute of Bragança, Campus de Santa Apolónia, \\ 1172, 5300-253 Bragança, Portugal; jpinela@ipb.pt (J.P.); lillian@ipb.pt (L.B.); amilcar@ipb.pt (A.L.A.); \\ anacarv@ipb.pt (A.M.C.) \\ 2 REQUIMTE/LAQV, Faculty of Pharmacy, University of Porto, Rua Jorge Viterbo Ferreira, \\ no. 228, 4050-313 Porto, Portugal; beatoliv@ff.up.pt \\ 3 Centro de Ciências e Tecnologias Nucleares (C2TN), Instituto Superior Técnico, Universidade de Lisboa, \\ E.N. 10, 2695-066 Bobadela, Portugal \\ * Correspondence: iferreira@ipb.pt; Tel.: +351-273-303-219; Fax: +351-273-325-405
}

Academic Editor: Derek J. McPhee

Received: 7 March 2016; Accepted: 7 April 2016; Published: 8 April 2016

\begin{abstract}
This study addresses the effects of gamma irradiation (1, 5 and $8 \mathrm{kGy})$ on color, organic acids, total phenolics, total flavonoids, and antioxidant activity of dwarf mallow (Malva neglecta Wallr.). Organic acids were analyzed by ultra fast liquid chromatography (UFLC) coupled to a photodiode array (PDA) detector. Total phenolics and flavonoids were measured by the Folin-Ciocalteu and aluminium chloride colorimetric methods, respectively. The antioxidant activity was evaluated based on the $\mathrm{DPPH}^{\bullet}$ scavenging activity, reducing power, $\beta$-carotene bleaching inhibition and thiobarbituric acid reactive substances (TBARS) formation inhibition. Analyses were performed in the non-irradiated and irradiated plant material, as well as in decoctions obtained from the same samples. The total amounts of organic acids and phenolics recorded in decocted extracts were always higher than those found in the plant material or hydromethanolic extracts, respectively. The $\mathrm{DPPH}^{\bullet}$ scavenging activity and reducing power were also higher in decocted extracts. The assayed irradiation doses affected differently the organic acids profile. The levels of total phenolics and flavonoids were lower in the hydromethanolic extracts prepared from samples irradiated at $1 \mathrm{kGy}$ (dose that induced color changes) and in decocted extracts prepared from those irradiated at $8 \mathrm{kGy}$. The last samples also showed a lower antioxidant activity. In turn, irradiation at $5 \mathrm{kGy}$ favored the amounts of total phenolics and flavonoids. Overall, this study contributes to the understanding of the effects of irradiation in indicators of dwarf mallow quality, and highlighted the decoctions for its antioxidant properties.
\end{abstract}

Keywords: Malva neglecta; ionizing radiation; color parameters; organic acids; antioxidant activity; decoction; quality control

\section{Introduction}

Organic acids are primary metabolites widely spread throughout the plant kingdom. Chemically, they are low weight molecules and are considered to be any organic carboxylic acid with a general structure R-COOH. Although they are weak acids, these water-soluble compounds may confer acidic properties to foods containing them and influence its organoleptic properties (flavor, color and aroma) and consequent acceptability by the consumers [1]. From a practical point of view, the organic acids profile (levels and relative ratios) is important for food quality control. It allows determining 
the percentage of plant added to final products, thus detecting adulterations or possible microbial deteriorations occurring during storage, providing a practical advantage for its use as an authenticity index in plant-based foods and beverages [1-3]. The relative amounts and the presence of each of these compounds are also useful as a means to evaluate the effect of food processing [2,4]. Thus, qualitative and quantitative analyses of these ingredients are of great importance.

During the production process (from harvesting and drying to packaging and storage), raw plants are prone to various contaminations and infestations, which can lead to spoilage, quality deterioration and consequent economic losses [5]. Besides constituting health hazards to consumers, contaminated products can also adversely affect the efficacy and stability of their bioactive ingredients and lead to spoilage of final products [6]. The presence of organic acids and phenolic compounds is advantageous, as they contribute to the natural preservation process (through its antimicrobial and antioxidant activities), but is not enough. The search for new preservation treatments with a minimum impact on physical, chemical and functional parameters highlighted the gamma irradiation as a safe, effective and sustainable option to sanitize plant products $[7,8]$.

Nowadays there is a growing scientific interest in irradiation-induced modifications of antioxidant properties and compounds responsible for such effects. The antioxidant activity is strongly linked the presence of phenolic compounds [9-12], secondary metabolites frequently found attached to sugars (glycosides), which increases their water solubility. These compounds have the ability to donate a hydrogen atom from the aromatic hydroxyl group to a free radical and/or the capacity to support an unpaired electron in their aromatic structures. Therefore, the methods used to evaluate the antioxidant activity can be classified according to the mechanism of action, i.e., single-electron transfer or hydrogen atom transfer [13]. However, phenolic compounds, organic acids and other bioactive constituents may be affected by irradiation treatment if applied inappropriately. It is known that ionizing radiation interacts with water molecules generating free radicals, in a reaction commonly known as radiolysis [14]. These free radicals can then interact with different biomolecules, leading to breakdown of chemical bonds and changes in their structure and, consequently, in the bioactivity and extractability from the plant material. The referred compounds may also be affected by the direct impact of the gamma-rays [14,15]. As a consequence, the color of the processed samples may change. However, this quality attribute is directly related to consumers' appreciation of a product, as they tend to associate its color with its taste, hygienic safety, shelf-life and personal satisfaction [16,17]. A very stringent plant selection based on color parameters also occurs in the food, pharmaceutical and cosmeceutical industries [18]. Therefore, the color evaluation is important in quality control parameter of irradiated products.

Dwarf mallow (Malva neglecta Wallr.) is an annual herbaceous plant of the family Malvaceae traditionally eaten raw as a leafy vegetable or prepared in herbal beverages (mainly decoctions) due to claims of disinfectant and anti-inflammatory effects [19]. It is also used to treat multiple medical conditions such as asthma, colds, digestive and urinary problems, and abdominal pains [20]. Scientific works have reported antioxidant [11,20], antibacterial [21] and anti-ulcerogenic [22] properties for this plant. Nevertheless, as far as we know, the organic acids profile of this plant remains unknown, as well as the effects induced by the gamma irradiation treatment on its physical or chemical properties. Thus, the main purpose of this study was to investigate the dose-response effects of gamma irradiation on color, organic acids, total phenolics and flavonoids, and antioxidant properties (quality control indicators) of $M$. neglecta samples. The influence of the preparation method (decoction) was also investigated.

\section{Results}

\subsection{Effects on Color Parameters}

The CIE $L^{*} a^{*} b^{*}$ color values for non-irradiated and irradiated samples of $M$. neglecta are presented in Figure 1. The 5 and $8 \mathrm{kGy}$ doses had no influence on color parameters. However, 
significant differences were found for samples irradiated with the $1 \mathrm{kGy}$ dose. These samples revealed lower lightness $\left(L^{*}=43.43 \pm 0.89\right)$ and yellowness $\left(b^{*}=22.29 \pm 0.96\right)$ and higher redness $\left(a^{*}=-12.69 \pm 0.45\right)$, which induced the more pronounced total color difference $\left(\Delta E^{*}=1.81\right)$, compared with the non-irradiated control samples $\left(L^{*}=45.07 \pm 0.97, b^{*}=23.98 \pm 0.55\right.$ and $\left.a^{*}=-13.84 \pm 0.29\right)$. Furthermore, while the $\Delta E^{*}$ up to 0.5 and from 0.5 to 1.5 indicate trace color differences and slight differences, respectively, the $\Delta E^{*}$ corresponding to the $1 \mathrm{kGy}$ dose indicates a noticeable difference detectable by the human eye [23].

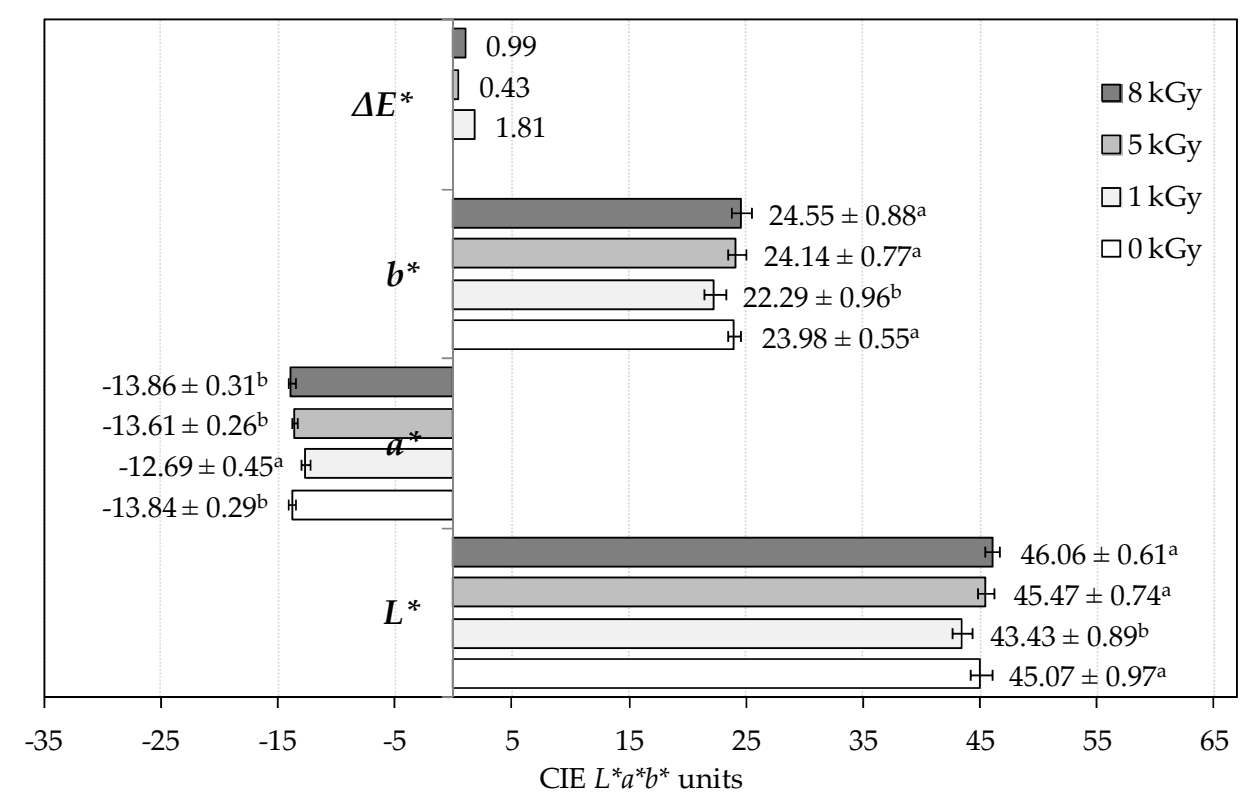

Figure 1. Impact of the gamma irradiation treatment on color parameters of M. neglecta powdered samples. $\Delta E^{*}$ : total color difference; $b^{*}$ : blueness $(-) \leftrightarrow$ yellowness $(+) ; a^{*}$ : greenness $(-) \leftrightarrow$ redness $(+)$; and $L^{*}$ : darkness $(0) \leftrightarrow$ lightness $(100)$. For each color parameter, different letters $(a, b)$ indicate statistically significant differences $(p<0.05)$.

Similar results were previously reported by Kirkin et al. [24]. Those authors found that the $7 \mathrm{kGy}$ dose had a greater effect on color parameters of Rosmarinus officinalis L. than higher doses of 12 and $17 \mathrm{kGy}$. In these samples, the $L^{*}$ value was decreased and the $a^{*}$ value was increased, in accordance to our results. The discoloration of Piper nigrum L. by decreasing the $a^{*}$ and $b^{*}$ values and increasing the $L^{*}$ value was also reported, as well as the suitability of the applied doses to maintain the color parameters of Thymus vulgaris L. and Cuminum cyminum L. A tendency for lightness decrease was also reported by Pereira et al. [25] in Ginkgo biloba L. samples irradiated at 10 kGy. Nevertheless, browning is unwanted in dried products [26]. On the other hand, Pinela et al. [9] reported that gamma irradiation treatment up to $10 \mathrm{kGy}$ had no effect on the color parameters of shade- and freeze-dried samples of Tuberaria lignosa (Sweet) Samp. Therefore, we can conclude that the irradiation-induced modifications on color parameters not only depend on the applied dose, but also on the plant material under investigation.

\subsection{Effects on Organic Acids}

Table 1 shows the organic acids content found in M. neglecta dry material submitted to gamma irradiation, as well as in the decocted extracts (the form traditionally used in folk medicine) prepared from that material. Oxalic, quinic, malic, citric, succinic and fumaric acids were quantified, being oxalic acid the most abundant organic acid (Figure 2). The total amounts recorded in the decocted extracts were always higher than those found in the plant dry material, as well as the individual levels of each organic acid (except for citric acid) (Table 1). This difference may be related to a better extraction 
efficiency achieved at elevated temperature, but that can lead to citric acid degradation [27]. These results are in agreement with those previously reported by Guimarães et al. [10] for Matricaria recutita L. dry material and decocted extracts.

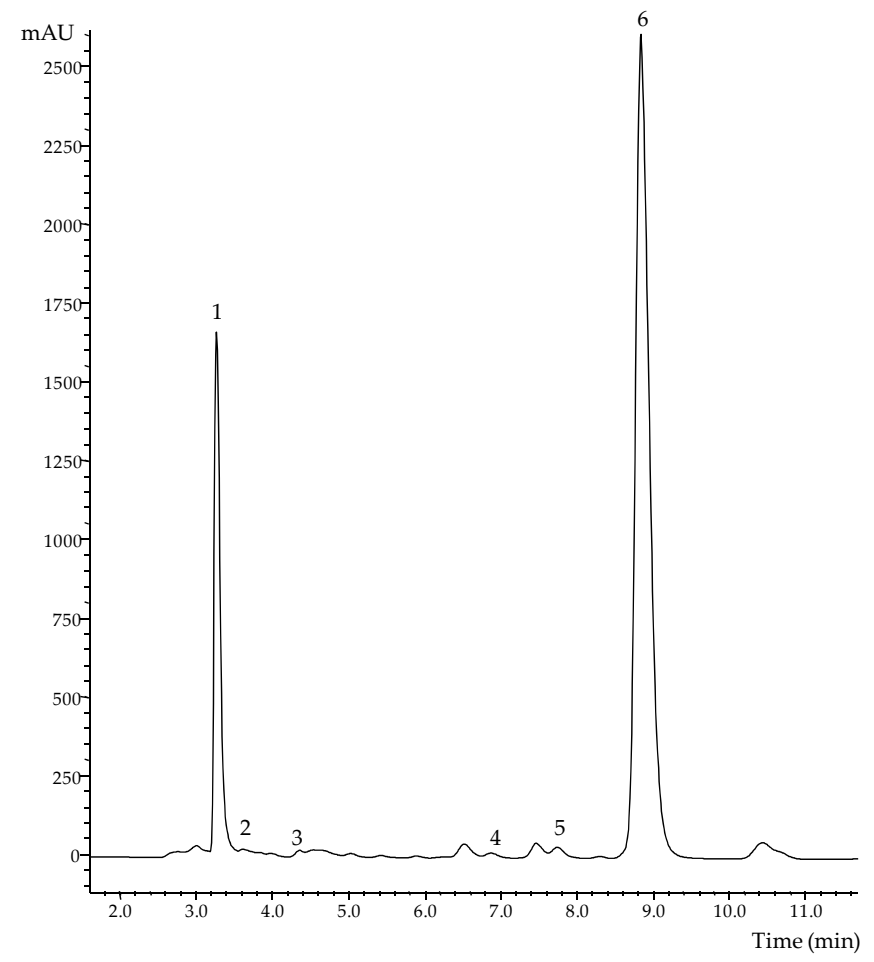

Figure 2. Chromatographic profile of organic acids in the decoction prepared from M. neglecta samples irradiated at $5 \mathrm{kGy}$, obtained using UFLC-PDA. Peak identification: 1: oxalic acid, 2: quinic acid, 3: malic acid, 4: citric acid, 5: succinic acid, and 6: fumaric acid.

Table 1. Organic acids content in the dry material and decocted extracts of M. neglecta samples submitted to gamma irradiation.

\begin{tabular}{|c|c|c|c|c|c|c|c|}
\hline Dose & Oxalic Acid & Quinic Acid & Malic Acid & Citric Acid & Succinic Acid & Fumaric Acid & Total \\
\hline \multicolumn{8}{|c|}{ Dry material (mg/g dw) } \\
\hline $0 \mathrm{kGy}$ & $67.50 \pm 0.16^{b}$ & $6.63 \pm 0.21^{b}$ & $3.16 \pm 0.28^{b}$ & $21.56 \pm 0.41^{b}$ & $7.50 \pm 0.13^{a}$ & $15.07 \pm 0.03^{c}$ & $121.43 \pm 1.17^{b}$ \\
\hline $5 \mathrm{kGy}$ & $65.30 \pm 0.17^{c}$ & $6.34 \pm 0.28^{b}$ & $3.42 \pm 0.33^{a b}$ & $22.28 \pm 0.31^{\mathrm{a}}$ & $7.29 \pm 0.12^{a}$ & $13.59 \pm 0.07^{\mathrm{d}}$ & $118.22 \pm 1.15^{c}$ \\
\hline $8 \mathrm{kGy}$ & $71.75 \pm 0.10^{\mathrm{a}}$ & $6.45 \pm 0.08^{b}$ & $3.64 \pm 0.05^{\mathrm{a}}$ & $19.02 \pm 0.08^{d}$ & $6.23 \pm 0.13^{b}$ & $15.85 \pm 0.05^{b}$ & $122.94 \pm 0.30 \mathrm{ab}$ \\
\hline 1 kGy & $79.80 \pm 0.05^{c}$ & $6.96 \pm 0.20^{c}$ & $10.52 \pm 0.08^{a}$ & $9.80 \pm 0.15^{b}$ & $47.36 \pm 0.38^{b}$ & $21.54 \pm 0.19^{b}$ & $175.99 \pm 0.89^{c}$ \\
\hline $5 \mathrm{kGy}$ & $88.72 \pm 0.03^{b}$ & $8.90 \pm 0.09^{a}$ & $9.72 \pm 0.19^{b}$ & $12.76 \pm 0.07^{a}$ & $54.17 \pm 0.06^{a}$ & $20.81 \pm 0.08^{c}$ & $195.09 \pm 0.01^{b}$ \\
\hline $8 \mathrm{kGy}$ & $106.33 \pm 0.10^{a}$ & $8.37 \pm 0.39^{b}$ & $7.89 \pm 0.29^{c}$ & $8.58 \pm 0.35^{c}$ & $41.42 \pm 0.50^{c}$ & $25.17 \pm 0.09^{a}$ & $197.76 \pm 0.95^{a}$ \\
\hline
\end{tabular}

The results are presented as mean \pm standard deviation. In each column and for each sample (dry material and decoction), different letters $(\mathrm{a}-\mathrm{d})$ indicate statistically significant differences $(p<0.05)$.

In the plant material, the relative amounts of oxalic, citric and fumaric acids were the most affected by the irradiation treatment (Table 1); however, this variation was more marked in the decocted extracts, mainly in the oxalic and succinic acids, probably due to the combined effects induced by gamma irradiation and preparation method. Therefore, the levels of organic acids and relative ratios in the decocted extracts were somewhat different from those found in the dry material, e.g., citric acid was the second most abundant organic acid in the plant material and presented a reduction of $\sim 12 \%$ in the decocted extracts, while the relative ratios of succinic acid increased $\sim 19 \%$ in those preparations. 
Nevertheless, although oxalic, malic, citric and fumaric acids have been already described in flowers and flowering shoots of Malva sylvestris L. [28], quinic and succinic acids were not detected or present in trace amounts in this species, so a qualitative analysis of the organic acids profile can be used to detect possible adulterations in the samples.

In the dry material, the $1 \mathrm{kGy}$ dose did not induce any adverse effect on the organic acids profile and increased the total levels. Lower amounts of total organic acids were however detected in samples irradiated at $5 \mathrm{kGy}$, due to a decrease of oxalic and fumaric acids. The highest levels of citric and succinic acids and a reduction of fumaric acid detected in both samples (dry material and decocted extract) were also associated with the $5 \mathrm{kGy}$ dose. Finally, the samples irradiated at $8 \mathrm{kGy}$ gave the highest levels of total organic acids. It can be concluded that, in general, the effects induced by the different doses were positive, as the decrease in total organic acids was mainly associated with the oxalic acid content. Despite the importance of this acid in the pharmaceutical industry [29], it has been associated with some health problems, e.g., oxalic acid can combine with calcium in the kidneys to form kidney stones in susceptible people [30].

The identified organic acids have been used as food additives or pharmaceutical and cosmetic excipients [31,32]. Citric acid is a widely used food additive in many kinds of beverages due to its mild and refreshing sourness [1,33], succinic acid is also used in the food industry as well as in pharmaceuticals and antibiotics [31], fumaric acid is used due to its effectiveness against psoriasis and inflammation and due to its neuro- and chemoprotective effects [34], and malic and citric acids are reported to have bactericidal effects [35]. Additionally, the consumption of these compounds in moderate amounts can promote appetite, help digestion and be beneficial to human health [4]. Nevertheless, excessive doses of certain organic acids should be avoided [32].

\subsection{Effects on Total Phenolics, Total Flavonoids and Antioxidant Activity}

The effects of gamma irradiation on the total phenolic and flavonoid contents and antioxidant activity of the M. neglecta hydromethanolic and decocted extracts can be accessed from the analysis of Table 2. The antioxidant activity results are expressed in $\mathrm{EC}_{50}$ values; thus, the lower the $\mathrm{EC}_{50}$ value, the higher the antioxidant activity. In general, the decocted extracts revealed higher amounts of total phenolics and flavonoids than the hydromethanolic extracts, as well as an increased DPPH ${ }^{\bullet}$ scavenging activity and reducing power. The samples irradiated at $1 \mathrm{kGy}$ and extracted with the hydromethanolic mixture revealed lower levels of both total phenolic and flavonoids and decreased $\mathrm{DPPH}^{\bullet}$ scavenging activity, reducing power, and TBARS formation inhibition capacity. This result is in agreement with the higher $\Delta E^{*}$ found in these samples. Contrariwise, the hydromethanolic extracts prepared from the samples irradiated at $5 \mathrm{kGy}$ revealed higher levels of total phenolics and flavonoids and an increased $\mathrm{DPPH}^{\bullet}$ scavenging activity and lipid peroxidation inhibition capacity (accessed by the $\beta$-carotene bleaching inhibition and TBARS formation inhibition in brain cell homogenates) in comparison with those prepared from the non-irradiated control samples. In fact, the lipid peroxidation inhibition capacity of these extracts was favored by the irradiation treatment (except for the TBARS formation inhibition of the extracts prepared from the samples irradiated at $1 \mathrm{kGy}$ ). This result can be explained by the affinity of these two in vitro assays for lipophilic antioxidants and by the fact that the irradiation treatment affects the different antioxidant molecules differently [14,15]. 
Table 2. Antioxidant activity of the hydromethanolic and decocted extracts prepared from the M. neglecta dry material submitted to gamma irradiation.

\begin{tabular}{|c|c|c|c|c|c|c|}
\hline Dose & $\begin{array}{l}\mathrm{DPPH}^{\bullet} \text { Scavenging Activity } \\
\left(\mathrm{EC}_{50} \text { values, } \mathrm{mg} / \mathrm{mL}\right)\end{array}$ & $\begin{array}{l}\text { Reducing Power }\left(\mathrm{EC}_{50}\right. \\
\text { values, } \mathrm{mg} / \mathrm{mL})\end{array}$ & $\begin{array}{c}\beta \text {-Carotene Bleaching } \\
\quad \text { Inhibition } \\
\left(\mathrm{EC}_{50} \text { values, } \mathrm{mg} / \mathrm{mL}\right)\end{array}$ & 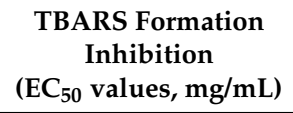 & $\begin{array}{l}\text { Total Phenolics } \\
\text { (mg GAE/g Extract) }\end{array}$ & $\begin{array}{l}\text { Total Flavonoids } \\
\text { (mg CE/g Extract) }\end{array}$ \\
\hline \multicolumn{7}{|c|}{ Hydromethanolic extracts } \\
\hline 0 kGy & $1.15 \pm 0.02^{c}$ & $0.52 \pm 0.01^{\mathrm{c}}$ & $0.46 \pm 0.01^{a}$ & $0.56 \pm 0.05^{b}$ & $69.54 \pm 0.21^{b}$ & $22.85 \pm 0.52^{b}$ \\
\hline $1 \mathrm{kGy}$ & $1.57 \pm 0.02^{b}$ & $0.69 \pm 0.01^{\mathrm{a}}$ & $0.41 \pm 0.03^{b}$ & $0.58 \pm 0.03^{\mathrm{a}}$ & $55.04 \pm 0.36^{\mathrm{d}}$ & $19.56 \pm 0.08^{c}$ \\
\hline $5 \mathrm{kGy}$ & $1.06 \pm 0.07^{\mathrm{d}}$ & $0.57 \pm 0.02^{b}$ & $0.41 \pm 0.01^{b}$ & $0.11 \pm 0.03^{d}$ & $78.55 \pm 0.67^{a}$ & $27.30 \pm 0.20^{a}$ \\
\hline $8 \mathrm{kGy}$ & $1.75 \pm 0.04^{\mathrm{a}}$ & $0.56 \pm 0.01^{b}$ & $0.40 \pm 0.01^{b}$ & $0.22 \pm 0.01^{c}$ & $64.78 \pm 1.51^{c}$ & $22.70 \pm 0.51^{b}$ \\
\hline \multicolumn{7}{|c|}{ Decocted extracts } \\
\hline $0 \mathrm{kGy}$ & $0.37 \pm 0.01^{c}$ & $0.268 \pm 0.002^{b}$ & $0.16 \pm 0.01^{\mathrm{c}}$ & $0.403 \pm 0.004^{b}$ & $91.05 \pm 1.14^{b}$ & $25.14 \pm 0.53^{b}$ \\
\hline $1 \mathrm{kGy}$ & $0.40 \pm 0.01^{b}$ & $0.264 \pm 0.003^{c}$ & $0.17 \pm 0.02^{c}$ & $0.35 \pm 0.01^{\mathrm{c}}$ & $96.92 \pm 3.73^{\mathrm{a}}$ & $28.03 \pm 0.07^{\mathrm{a}}$ \\
\hline $5 \mathrm{kGy}$ & $0.36 \pm 0.01^{\mathrm{c}}$ & $0.253 \pm 0.003^{d}$ & $0.41 \pm 0.01^{b}$ & $0.32 \pm 0.01^{d}$ & $96.76 \pm 0.60^{a}$ & $27.63 \pm 0.35^{a}$ \\
\hline $8 \mathrm{kGy}$ & $0.46 \pm 0.02^{a}$ & $0.326 \pm 0.001^{a}$ & $0.46 \pm 0.01^{\mathrm{a}}$ & $0.69 \pm 0.02^{a}$ & $78.99 \pm 0.30^{c}$ & $21.98 \pm 0.47^{c}$ \\
\hline
\end{tabular}

The results are presented as mean \pm standard deviation. In each column and for each sample (hydromethanolic and decocted extracts), different letters (a-d) indicate statistically significant differences $(p<0.05)$. $\mathrm{EC}_{50}$ : Extract concentration corresponding to $50 \%$ of antioxidant activity or 0.5 of absorbance in the reducing power assay. Trolox EC $\mathrm{C}_{50}$ values: $42 \mu \mathrm{g} / \mathrm{mL}$ (DPPH ${ }^{\bullet}$ scavenging activity), $41 \mu \mathrm{g} / \mathrm{mL}$ (reducing power), $18 \mu \mathrm{g} / \mathrm{mL}$ ( $\beta$-carotene bleaching inhibition) and $23 \mu \mathrm{g} / \mathrm{mL}$ (TBARS inhibition). GAE: gallic acid equivalents;

CE: catechin equivalents. 
Regarding the decocted extracts, the 8 kGy dose decreased the antioxidant properties and levels of total phenolics and flavonoids. However, the other assayed doses reinforced the reducing power, the TBARS formation inhibition capacity, and the levels of total phenolics and flavonoids. Similar trends have been observed in other studies. A higher $\mathrm{DPPH}^{\bullet}$ scavenging activity and reducing power of decocted and infused extracts of T. vulgaris, compared to the hydroalcoholic ones, was found by Martins et al. [12]. Decoction was also the preferable preparation method for obtaining increased levels of phenolic acids and flavonoids. The suitability of decoctions and infusions for extracting phenolic compounds from commercial samples of Achillea millefolium L. was demonstrated by Dias et al. [36], who prepared aqueous extracts that also had interesting antioxidant properties. Furthermore, despite the plant extracts rich in phenolic compounds are commonly referred to as having increased antioxidant properties [9-11], the presence of organic acids, as phenolics, may also contribute to these effects [37].

The total phenolic and flavonoid contents of different parts of $M$. neglecta were already reported by Dalar et al. [11] for samples from the Eastern Anatolia Region of Turkey. Lower total phenolic contents of $17.4 \pm 0.3 \mathrm{mg} \mathrm{GAE} / \mathrm{g}$ extract and $6.6 \pm 0.3 \mathrm{mg} \mathrm{GAE} / \mathrm{g}$ extract were reported in leaf and whole plant extracts, respectively, obtained using acidified methanol $(80 \%$ methanol and $1 \% \mathrm{HCl}(v / v)$ in water) as extraction solvent. Regarding total flavonoids, $7.21 \pm 0.28 \mathrm{mg} \mathrm{RE}$ (rutin equivalents)/g extract and $2.95 \pm 0.16 \mathrm{mg} \mathrm{RE} / \mathrm{g}$ extract were found in the leaf and whole plant extracts, respectively. The same authors also evaluated the antioxidant activity through the ferric reducing antioxidant power (FRAP) and oxygen radical absorbance capacity (ORAC) assays. The highest bioactivity was assigned to the leaf extracts and then to the flower extracts. These differences in the phenolic content may be justified by variations in edafoclimatic conditions of the locations where the samples were collected, which may affect the plant composition during the growing season [38]. Additionally, as verified in our study, the extraction method also causes significant variations in the evaluated responses. The used of different variables in obtaining hydromethanolic and decocted extracts, namely different solvents, extraction times, temperatures, and sample to solvent ratios, may have favored the extraction of different molecules.

Although nothing has been reported on the impact of gamma irradiation on the antioxidant activity or phenolic composition of M. neglecta, different effects have been reported in other plant materials. A study conducted by Pinela et al. [9] concluded that irradiation doses up to $10 \mathrm{kGy}$ did not significantly affect the antioxidant activity and phenolic composition of decoctions and infusions prepared from T. lignosa samples. On the other hand, Pereira et al. reported increased antioxidant properties in infusions and methanolic extracts of borututu (Cochlospermum angolensis Welw.) [39] and G. biloba samples [25] irradiated at $10 \mathrm{kGy}$, respectively. The authors also verified that the $10 \mathrm{kGy}$ dose improves the extractability of phenolic compounds from the G. biloba samples [40]. An increased total phenolic content and enhanced antioxidant activity of gamma irradiated almond skins extracted with $40 \%$ ethanol was reported by Harrison and Were [41]. Those authors attributed these results to the release of phenolic compounds from glycosidic components and degradation of larger phenolic compounds into smaller ones by the gamma irradiation treatment. In fact, the direct impact of gamma-rays and the indirect action of radiolytic products may change the structure of different antioxidant molecules and/or break some chemical bonds, thus leading to its decomposition or altered extractability from the plant material $[15,25,41]$. That is why the bioactivity of irradiated samples can either decrease or improve.

\section{Materials and Methods}

\subsection{Dosimeters, Standards and Reagents}

Amber Perspex routine dosimeters, Batch V, were purchased from Harwell Company (Oxfordshire, UK). Organic acids (oxalic, quinic, malic, citric, succinic and fumaric acids) and Trolox (6-hydroxy-2,5,7,8-tetramethylchroman-2-carboxylic acid) were purchased from Sigma (St. Louis, MO, USA). 2,2-Diphenyl-1-picrylhydrazyl (DPPH ${ }^{\bullet}$ ) was obtained from Alfa Aesar (Ward Hill, MA, USA). 
All other chemicals and solvents were of analytical grade and purchased from common sources. Water was treated in a Model A10 Milli-Q water purification system (Millipore, Billerica, MA, USA).

\subsection{Sample Collectionand Irradiation Experiments}

Plant material (leafy flowering stems) from dwarf mallow (Malva neglecta Wallr. Fam. Malvaceae) was sustainably harvested from the wild in June at Miranda do Douro, Northeastern Portugal, considering local medicinal uses as well as healers' and selected consumers' criteria, which are related to particular gathering sites and requirements for safe herbal dosages forms, namely decoctions [42]. Taxonomic identification of the plant material was confirmed by Dr. Ana Maria Carvalho from the Polytechnic Institute of Bragança, Portugal. A voucher specimen was deposited in the Herbarium of the School of Agriculture of Bragança. Samples were then lyophilized (FreeZone 4.5, Labconco, Kansas City, MO, USA), reduced to a fine dried powder (20 mesh) and mixed to obtain a homogeneous sample.

The obtained powdered sample was divided into four portions and submitted to 1,5 and $8 \mathrm{kGy}$ of gamma-rays (predicted doses). A non-irradiated control (0 kGy) followed all the experiments. The irradiation was performed in a cobalt-60 experimental chamber (Precisa 22, Graviner Manufacturing Company Ltd., London, UK) located at the University of Lisbon Centre for Nuclear Sciences and Technologies (C2TN, Lisbon, Portugal), with four sources and a total activity of $177 \mathrm{TBq}(4.78 \mathrm{kCi}$; January 2014). During the irradiation process, Amber Perspex routine dosimeters were used to measure the distribution of the absorbed energy and to determine the maximum $\left(D_{\max }\right)$ and the minimum $\left(D_{\min }\right)$ dose absorbed by the samples, following the procedure previously described by Fernandes et al. [43]. The measured average doses were $1.10 \pm 0.16 \mathrm{kGy}, 4.82 \pm 0.10 \mathrm{kGy}$ and $8.07 \pm 0.46 \mathrm{kGy}$ for the samples irradiated at the predicted doses of 1,5 and $8 \mathrm{kGy}$, respectively. The estimated dose rate for the irradiation position, obtained with a Fricke dosimeter [43], was $1.9 \mathrm{kGy} / \mathrm{h}$ and the dose uniformity ratio $\left(D_{\max } / D_{\min }\right)$ was 1.2 . For simplicity, the predicted doses were considered in the text.

\subsection{Color Measurement}

The powdered samples were placed on a adapter for granular materials (model CR-A50, Konica Minolta Sensing, Inc., Sakai, Osaka, Japan) to reduce external interferences and data were collected in three different points on each set of samples with a colorimeter (model CR-400, Konica) previously calibrated using the standard white plate. Using illuminant $C$ and the diaphragm opening of $8 \mathrm{~mm}$, the CIE $L^{*} a^{*} b^{*}$ color space values were registered through the computerized system using the SpectraMagic $\mathrm{Nx}$ (version CM-S100W) color data software. Average values were considered to determine the color coordinates, where $L^{*}$ represents lightness, $a^{*}$ represents chromaticity on a green $(-)$ to red $(+)$ axis, and $b^{*}$ represents chromaticity on a blue $(-)$ to yellow $(+)$ axis. The total color difference $\left(\Delta E^{*}\right)$ was calculated according to the CIEDE2000 equation [44].

\subsection{Preparation of Decoctions and Hydromethanolic Extracts}

Decoctions were prepared according to folk recipes/formulations [42]. Briefly, each powdered sample $(1 \mathrm{~g})$ was added to distilled water $(200 \mathrm{~mL})$ and boiled for $5 \mathrm{~min}$. The mixture was left to stand at room temperature for $5 \mathrm{~min}$ more and then was filtered through Whatman No. 4 paper. The obtained decoctions were frozen and lyophilized.

Hydromethanolic extractions were performed by stirring each powdered sample $(1 \mathrm{~g})$ with methanol/water $(30 \mathrm{~mL}, 80: 20, v / v)$ at $25^{\circ} \mathrm{C}$ and $150 \mathrm{rpm}$ for $1 \mathrm{~h}$. After filtering the supernatant through Whatman No. 4 paper, the residue was extracted with an additional portion $(30 \mathrm{~mL})$ of the hydromethanolic mixture. The combined extracts were concentrated under reduced pressure (R-210 rotary evaporator, Büchi, Flawil, Switzerland) and then frozen and lyophilized.

The lyophilized decocted and hydromethanolic extracts were redissolved in water and methanol/water $(80: 20, v / v)$, respectively, to obtain $4 \mathrm{mg} / \mathrm{mL}$ stock solutions which were successively diluted to different concentrations for evaluation of the antioxidant activity and total phenolics and flavonoids. 


\subsection{Analysis of Organic Acids}

Organic acids were analyzed by ultra fast liquid chromatography (UFLC) coupled with photodiode array (PDA) detection according to the procedures previously described by Pereira et al. [28]. Briefly, the powdered samples $(\sim 1 \mathrm{~g})$ were extracted by stirring with metaphosphoric acid $\left(25 \mathrm{~mL}, 25^{\circ} \mathrm{C}\right.$ at $\left.150 \mathrm{rpm}\right)$ for $45 \mathrm{~min}$ and then subsequently filtering through Whatman No. 4 paper. For decoctions, the lyophilized extracts $(\sim 10 \mathrm{mg})$ were dissolved in metaphosphoric acid $(1 \mathrm{~mL})$. All samples were filtered through $0.2 \mu \mathrm{m}$ nylon filters before analysis. The organic acids found were quantified by comparison of the area of their peaks recorded at $215 \mathrm{~nm}$ with calibration curves obtained from commercial standards of each compound. The results were expressed in mg per $\mathrm{g}$ of dry weight or lyophilized decoction (dw).

\subsection{Evaluation of the Total Phenolic and Flavonoid Content}

The total phenolic content was determined in the hydromethanolic and decocted extracts concentrated at $1.25 \mathrm{mg} / \mathrm{mL}$ by the Folin-Ciocalteu method [45,46] with slight modifications [47]. This assay is based on the formation of a blue-colored complex between the molybdenum and tungsten present in the Folin-Ciocalteu reagent upon reaction with reducing agents, which is monitored at $765 \mathrm{~nm}$. The standard curve was calculated using gallic acid and the results were expressed as $\mathrm{mg}$ of gallic acid equivalents (GAE) per g of extract.

The total flavonoid content was determined in the hydromethanolic and decocted extracts concentrated at $2.5 \mathrm{mg} / \mathrm{mL}$ using the aluminium chloride colorimetric method [48] with slight modifications as described by the authors [49]. This assay is based on the formation of a flavonoid-aluminium complex, which is monitored at $510 \mathrm{~nm}$. The standard curve was calculated using catechin and the results were expressed as mg of catechin equivalents (CE) per $g$ of extract.

\subsection{Evaluation of the Antioxidant Activity}

The hydromethanolic and decocted extracts at different concentrations were submitted to four distinct in vitro assays to evaluate its antioxidant capacity [9]. Briefly, the DPPH ${ }^{\bullet}$ scavenging activity and the reducing power assays were performed using an ELX800 Microplate Reader (Bio-Tek Instruments, Inc.; Winooski, VT, USA). The reduction of DPPH ${ }^{\bullet}$ was determined after incubation of the different extracts with a methanolic solution containing DPPH $\left(6 \times 10^{-5} \mathrm{M}\right)$ for $60 \mathrm{~min}$ in the dark by measuring the absorbance at $515 \mathrm{~nm}$. The radical scavenging activity (RSA) was calculated as a percentage of $\mathrm{DPPH}^{\bullet}$ discoloration using the Equation (1):

$$
\operatorname{RSA}(\%)=\left[\left(\mathrm{A}_{\mathrm{DPPH}}-\mathrm{A}_{\mathrm{S}}\right) / \mathrm{A}_{\mathrm{DPPH}}\right] \times 100
$$

where $A_{D P P H}$ is the absorbance of the $\mathrm{DPPH}^{\bullet}$ solution and $\mathrm{A}_{\mathrm{S}}$ is the absorbance of the solution containing the sample extract. The reducing power was evaluated by the ferricyanide/Prussian blue assay, whereby the capacity of the extracts to convert potassium ferricyanide $\left(\mathrm{K}_{3}\left[\mathrm{Fe}(\mathrm{CN})_{6}\right]\right)$ into potassium ferrocyanide $\left(\mathrm{K}_{4}\left[\mathrm{Fe}(\mathrm{CN})_{6}\right]\right)$, which then reacts with ferric chloride $\left(\mathrm{FeCl}_{3}\right)$ to form a ferric-ferrous complex that is measuring spectrophotometrically, was monitored at $690 \mathrm{~nm}$. The $\beta$-carotene bleaching inhibition (CBI) was evaluated by measuring the capacity of the extracts to neutralize linoleate free radicals. The different extracts were mixed with an emulsion containing $\beta$-carotene, linoleic acid and Tween 80 emulsifier and the absorbance was immediately measured at $470 \mathrm{~nm}$ in a Model 200 spectrophotometer (Analytik Jena, Jena, Germany). After $2 \mathrm{~h}$ of incubation at $50{ }^{\circ} \mathrm{C}$, the absorbance was read again. The CBI was calculated using the Equation (2):

$$
\mathrm{CBI}(\%)=\left(\mathrm{A}_{120} / \mathrm{A}_{0}\right) \times 100
$$

where $A_{120}$ is the absorbance of the emulsion after $2 \mathrm{~h}$ of incubation and $\mathrm{A}_{0}$ is the initial absorbance. The thiobarbituric acid reactive substances (TBARS) formation inhibition was evaluated in porcine brain 
homogenates. The color intensity of the malondialdehyde-thiobarbituric acid (MDA-TBA) complex formed during heating of the reaction mixture at $80^{\circ} \mathrm{C}$ was measured at $532 \mathrm{~nm}$. The inhibition ratio was calculated using the Equation (3):

$$
\text { Inhibition ratio }(\%)=[(\mathrm{A}-\mathrm{B}) / \mathrm{A}] \times 100
$$

where $\mathrm{A}$ and $\mathrm{B}$ correspond to the absorbance of the control and the sample solution, respectively. The results were expressed in $\mathrm{EC}_{50}$ values $(\mathrm{mg} / \mathrm{mL})$, i.e., sample concentration providing $50 \%$ of antioxidant activity or 0.5 of absorbance in the reducing power assay. Trolox was used as positive control.

\subsection{Statistical Analysis}

In all cases, analyses were carried out using three samples separately processed, and all the assays were carried out in triplicate. The results were expressed as mean \pm standard deviation and analyzed using one-way analysis of variance (ANOVA) followed by Tukey's HSD test with $\alpha=0.05$. This treatment was carried out using IBM SPSS Statistics for Windows, Version 22.0 (IBM Corp., Armonk, NY, USA).

\section{Conclusions}

This study demonstrated the adequacy of gamma irradiation at 5 and $8 \mathrm{kGy}$ to preserve the color parameters of M. neglecta dry material. Moreover, it was confirmed that the observed irradiation-induced modifications of color parameters not only depend on the applied dose, but also on the plant material under study. Oxalic, quinic, malic, citric, succinic and fumaric acids were identified in this plant for the first time. The total levels recorded in decocted extracts were always higher than those found in the plant dry material, as well as the individual levels of each organic acid (except for citric acid). Irradiation at $5 \mathrm{kGy}$ increased the amounts of citric and succinic acids and decreased the fumaric acid levels in both matrices. In general, decoctions were preferred for their higher levels of total phenolics and flavonoids, $\mathrm{DPPH}^{\bullet}$ scavenging activity and reducing power. In these preparations, the antioxidant properties and levels of total phenolics and flavonoids were decreased with the $8 \mathrm{kGy}$ dose. In turn, the hydromethanolic extracts obtained from samples irradiated at $1 \mathrm{kGy}$ showed decreased levels of total phenolic, total flavonoids, and lower antioxidant properties. Thus, decoctions were highlighted by interesting antioxidant properties and levels of total phenolics and organic acids. Nevertheless, further studies are of interest to evaluate the decontamination effectiveness of this technology and to investigate the effect in other quality parameters.

Acknowledgments: The authors are grateful to PRODER research project no. 53514, AROMAP, for financial support of the work and to the Foundation for Science and Technology (FCT, Portugal) for financial support to CIMO (PEst-OE/AGR/UI0690/2014), REQUIMTE (UID/QUI/50006/2013), C2TN (RECI/AAG-TEC/0400/2012), J. Pinela (SFRH/BD/92994/2013) and L. Barros (SFRH/BPD/107855/2015).

Author Contributions: J. Pinela, L. Barros, A.L. Antonio and I.C.F.R. Ferreira designed the experiments; A.M. Carvalho performed the taxonomic identification of the species; A.L. Antonio performed the irradiation treatment; J. Pinela and L. Barros performed the analytical assays and analyzed the data; J. Pinela and I.C.F.R. Ferreira wrote the manuscript; A.L. Antonio, A.M. Carvalho and M.B.P.P. Oliveira revised the manuscript.

Conflicts of Interest: The authors declare no conflict of interest.

\section{References}

1. Andrés, V.; Tenorio, M.D.; Villanueva, M.J. Sensory profile, soluble sugars, organic acids, and mineral content in milk- and soy-juice based beverages. Food Chem. 2015, 173, 1100-1106. [CrossRef] [PubMed]

2. Silva, B.M.; Andrade, P.B.; Mendes, G.C.; Seabra, R.M.; Ferreira, M.A. Study of the organic acids composition of quince (Cydonia oblonga Miller) fruit and jam. J. Agric. Food Chem. 2002, 50, 2313-2317. [CrossRef] [PubMed]

3. Ehling, S.; Cole, S. Analysis of organic acids in fruit juices by liquid chromatography-mass spectrometry: An enhanced tool for authenticity testing. J. Agric. Food Chem. 2014, 59, 2229-2234. [CrossRef] [PubMed] 
4. Nawirska-Olszańska, A.; Biesiada, A.; Sokół-Łętowska, A.; Kucharska, A.Z. Characteristics of organic acids in the fruit of different pumpkin species. Food Chem. 2014, 148, 415-419. [CrossRef] [PubMed]

5. Darfour, B.; Agbenyegah, S.; Ofosu, D.O.; Okyere, A.A.; Asare, I.K. Gamma irradiation of Tetrapleura tetraptera fruit as a post-harvest technique and its subsequent effect on some phytochemicals, free scavenging activity and physicochemical properties. Radiat. Phys. Chem. 2014, 102, 153-158. [CrossRef]

6. Aouidi, F.; Ayari, S.; Ferhi, H.; Roussos, S.; Hamdi, M. Gamma irradiation of air-dried olive leaves: Effective decontamination and impact on the antioxidative properties and on phenolic compounds. Food Chem. 2011, 127, 1105-1113. [CrossRef] [PubMed]

7. WHO. High-Dose Irradiation: Wholesomeness of Food Irradiated with Doses above 10 kGy, Report of a Joint FAO/IAEA/WHO Study Group. WHO technical Report Series 890; World Health Organization: Geneva, Switzerland, 1999.

8. Fernandes, A.; Antonio, A.L.; Oliveira, M.B.P.P.; Martins, A.; Ferreira, I.C.F.R. Effect of gamma and electron beam irradiation on the physico-chemical and nutritional properties of mushrooms: A review. Food Chem. 2014, 135, 641-650. [CrossRef] [PubMed]

9. Pinela, J.; Antonio, A.L.; Barros, L.; Barreira, J.C.M.; Carvalho, A.M.; Oliveira, M.B.P.P.; Santos-Buelga, C.; Ferreira, I.C.F.R. Combined effects of gamma-irradiation and preparation method on antioxidant activity and phenolic composition of Tuberaria lignosa. RSC Adv. 2015, 5, 14756-14769. [CrossRef]

10. Guimarães, R.; Barros, L.; Duenas, M.; Calhelha, R.C.; Carvalho, A.M.; Santos-Buelga, C.; Queiroz, M.J.R.P.; Ferreira, I.C.F.R. Infusion and decoction of wild German chamomile: Bioactivity and characterization of organic acids and phenolic compounds. Food Chem. 2013, 136, 947-954. [CrossRef] [PubMed]

11. Dalar, A.; Türker, M.; Konczak, I. Antioxidant capacity and phenolic constituents of Malva neglecta Wallr. and Plantago lanceolata L. from Eastern Anatolia Region of Turkey. J. Herb. Med. 2012, 2, 42-51. [CrossRef]

12. Martins, N.; Barros, L.; Santos-Buelga, C.; Silva, S.; Henriques, M.; Ferreira, I.C.F.R. Decoction, infusion and hydroalcoholic extract of cultivated thyme: Antioxidant and antibacterial activities, and phenolic characterisation. Food Chem. 2015, 167, 131-137. [CrossRef] [PubMed]

13. Carocho, M.; Ferreira, I.C.F.R. A review on antioxidants, prooxidants and related controversy: Natural and synthetic compounds, screening and analysis methodologies and future perspectives. Food Chem. Toxicol. 2013, 51, 15-25. [CrossRef] [PubMed]

14. Harder, M.N.C.; Arthur, V.; Arthur, P.B. Irradiation of foods: Processing technology and effects on nutrients: Effect of ionizing radiation on food components. In Encyclopedia of Food and Health; Caballero, B., Finglas, P.M., Toldrá, F., Eds.; Academic Press: Oxford, UK, 2016; pp. 476-481.

15. Alothman, M.; Bhat, R.; Karim, A.A. Effects of radiation processing on phytochemicals and antioxidants in plant produce. Trends Food Sci. Technol. 2009, 20, 201-212. [CrossRef]

16. Śledź, M.; Nowacka, M.; Wiktor, A.; Witrowa-Rajchert, D. Selected chemical and physico-chemical properties of microwave-convective dried herb. Food Bioprod. Process. 2013, 91, 421-428. [CrossRef]

17. Sturm, B.; Vega, A.-M.N.; Hofacker, W.C. Influence of process control strategies on drying kinetics, colour and shrinkage of air dried apples. Appl. Therm. Eng. 2014, 62, 455-460. [CrossRef]

18. Jo, C.; Son, J.H.; Lee, H.J.; Byun, M.-W. Irradiation application of color removal and purification of green tea leave extract. Radiat. Phys. Chem. 2003, 66, 179-184. [CrossRef]

19. Carvalho, A.M.; Morales, R. Persistence of wild food and wild medicinal plant knowledge in a north-eastern region of Portugal. In Ethnobotany in the New Europe: People, Health and Wild Plant Resources; Pardo de Santayana, M., Pieroni, A., Puri, R., Eds.; Berghahn Books: Oxford, UK, 2013; pp. 147-171.

20. Türker, M.; Dalar, A. In vitro antioxidant and enzyme inhibitory properties and phenolic composition of $M$. neglecta Wallr. (Malvaceae) fruit: A traditional medicinal fruit from Eastern Anatolia. Ind. Crop Prod. 2013, 51, 376-380. [CrossRef]

21. Seyyednejad, S.M.; Koochak, H.; Darabpour, E.; Motamedi, H. A survey on Hibiscus rosa-sinensis, Alcea rosea L. and Malva neglecta Wallr as antibacterial agents. Asian Pac. J. Trop Med. 2010, 3, 351-355. [CrossRef]

22. Gürbüz, I.; Ozkan, A.M.; Yesilada, E.; Kutsal, O. Anti-ulcerogenic activity of some plants used in folk medicine of Pinarbasi (Kayseri, Turkey). J. Ethnopharmacol. 2005, 101, 313-318. [CrossRef] [PubMed]

23. Chen, X.D.; Mujumdar, A.S. Drying Technologies in Food Processing; Blackwell Publishing Ltd.: Oxford, UK, 2008.

24. Kirkin, C.; Mitrevski, B.; Gunes, G.; Marriott, P.J. Combined effects of gamma-irradiation and modified atmosphere packaging on quality of some spices. Food Chem. 2014, 154, 255-261. [CrossRef] [PubMed] 
25. Pereira, E.; Barros, L.; Antonio, L.; Bento, A.; Ferreira, I.C.F.R. Analytical methods applied to assess the effects of gamma irradiation on color, chemical composition and antioxidant activity of Ginkgo biloba L. Food Anal. Method 2015, 8, 154-163. [CrossRef]

26. Rahimmalek, M.; Goli, S.A.H. Evaluation of six drying treatments with respect to essential oil yield, composition and color characteristics of Thymys daenensis subsp. daenensis. Celak leaves. Ind. Crop. Prod. 2013, 42, 613-619. [CrossRef]

27. Reda, S.Y. Evaluation of antioxidants stability by thermal analysis and its protective effect in heated edible vegetable oil. Ciên. Tecnol. Aliment. 2011, 31, 475-480. [CrossRef]

28. Pereira, C.; Barros, L.; Carvalho, A.M.; Ferreira, I.C.F.R. Use of UFLC-PDA for the analysis of organic acids in thirty five species of food and medicinal plants. Food Anal. Method 2013, 6, 1337-1344. [CrossRef]

29. Lian, H.Z.; Mao, L.; Ye, X.L.; Miao, J. Simultaneous determination of oxalic, fumaric, maleic and succinic acids in tartaric and malic acids for pharmaceutical use by ion-suppression reversed-phase high performance liquid chromatography. J. Pharm. Biomed. 1999, 19, 621-625. [CrossRef]

30. Robitaille, L.; Mamer, O.A.; Miller, W.H., Jr.; Levine, M.; Assouline, S.; Melnychuk, D.; Rousseau, C.; Hoffer, L.J. Oxalic acid excretion after intravenous ascorbic acid administration. Metabolism 2009, 58, $263-269$. [CrossRef] [PubMed]

31. Sauer, M.; Porro, D.; Mattanovich, D.; Branduardi, P. Microbial production of organic acids: Expanding the markets. Trends Biotechnol. 2008, 26, 100-108. [CrossRef] [PubMed]

32. Carocho, M.; Barreiro, M.F.; Morales, P.; Ferreira, I.C.F.R. Adding molecules to food, pros and cons: A review on synthetic and natural food additives. Compr. Rev. Food Sci. F 2014, 13, 377-399. [CrossRef]

33. Liu, F.-J.; Ding, G.-S.; Tang, A.-N. Simultaneous separation and determination of five organic acids in beverages and fruits by capillary electrophoresis using diamino moiety functionalized silica nanoparticles as pseudostationary phase. Food Chem. 2014, 145, 109-114. [CrossRef] [PubMed]

34. Baati, T.; Horcajada, P.; Gref, R.; Couvreur, P.; Serre, C. Quantification of fumaric acid in liver, spleen and unrine by high-performance liquid chromatography coupled to photodiode-array detection. J. Pharm. Biomed. Anal. 2011, 56, 758-762. [CrossRef] [PubMed]

35. Raybaudi-Massilia, R.M.; Mosqueda-Melgar, J.; Martín-Belloso, O. Antimicrobial activity of malic acid against Listeria monocytogenes, Salmonella Enteritidis and Escherichia coli O157:H7 in apple, pear and melon juices. Food Control. 2009, 20, 105-112. [CrossRef]

36. Dias, M.I.; Barros, L.; Dueñas, M.; Pereira, E.; Carvalho, A.M.; Alves, R.C.; Oliveira, M.B.; Santos-Buelga, C.; Ferreira, I.C.F.R. Chemical composition of wild and commercial Achillea millefolium L. and bioactivity of the methanolic extract, infusion and decoction. Food Chem. 2013, 141, 4152-4160. [CrossRef] [PubMed]

37. Silva, B.M.; Andrade, P.B.; Valentão, P.; Ferreres, F.; Seabra, R.M.; Ferreira, M.A. Quince (Cydonia oblonga Miller) fruit (pulp, peel, and seed) and jam: Antioxidant activity. J. Agric. Food Chem. 2004, 52, 4705-4712. [CrossRef] [PubMed]

38. Nikolopoulou, D.; Grigorakis, K.; Stasini, M.; Alexis, M.N.; Iliadis, K. Differences in chemical composition of field pea (Pisum sativum) cultivars: Effects of cultivation area and year. Food Chem. 2007, 103, 847-852. [CrossRef]

39. Pereira, C.; Calhelha, R.C.; Antonio, A.L.; Queiroz, M.J.R.P.; Barros, L.; Ferreira, I.C.F.R. Effects of gamma radiation on chemical and antioxidant properties, anti-hepatocellular carcinoma activity and hepatotoxicity of borututu. Innov. Food Sci.Emerg. 2014, 26, 271-277. [CrossRef]

40. Pereira, E.; Barros, L.; Dueñas, M.; Antonio, A.L.; Santos-Buelga, C.; Ferreira, I.C.F.R. Gamma irradiation improves the extractability of phenolic compounds in Ginkgo biloba L. Ind. Crops Prod. 2015, 74, 144-149. [CrossRef]

41. Harrison, K.; Were, L.M. Effect of gamma irradiation on total phenolic content yield and antioxidant capacity of Almond skin extracts. Food Chem. 2007, 102, 932-937. [CrossRef]

42. Carvalho, A.M. Plantas y Sabiduría Popular del Parque. Natural de Montesinho Un estudio etnobotánico en Portugal; Biblioteca de Ciencias no. 35. Consejo Superior de Investigaciones Científicas: Madrid, Spain, 2010.

43. Fernandes, A.; Antonio, A.L.; Barreira, J.C.M.; Botelho, M.L.; Oliveira, M.B.P.P.; Martins, A.; Ferreira, I.C.F.R. Effects of gamma irradiation on the chemical composition and antioxidant activity of Lactarius deliciosus L. wild edible mushroom. Food Bioprocess. Technol. 2013, 6, 2895-2903. [CrossRef] 
44. ISO/CIE 11664-6:2014(E). Joint ISO/CIE Standard: Colorimetry-Part. 6: CIEDE2000 Colour-Difference Formula; International Organization for Standardization (ISO)/Commission Internationale de l'Éclairage (CIE): Geneva, Switzerland, 2014.

45. Singleton, V.L.; Rossi, J.A., Jr. Colorimetry of total phenolics with phosphomolybdic-phosphotungstic acid reagents. Am. J. Enol. Vitic. 1965, 16, 144-158.

46. Impei, S.; Gismondi, A.; Canuti, L.; Canini, A. Metabolic and biological profile of autochthonous Vitis vinifera L. ecotypes. Food Funct. 2015, 6, 1526-1538. [CrossRef] [PubMed]

47. Pereira, C.; Barros, L.; Carvalho, A.M.; Ferreira, I.C.F.R. Nutritional composition and bioactive properties of commonly consumed wild greens: Potential sources for new trends in modern diets. Food Res. Int. 2011, 44, 2634-2640. [CrossRef]

48. Chang, C.-C.; Yang, M.-H.; Wen, H.-M.; Chern, J.-C. Estimation of total flavonoid content in propolis by two complementary colorimetric methods. J. Food Drug Anal. 2002, 10, 178-182.

49. Barros, L.; Carvalho, A.M.; Sá Morais, J.; Ferreira, I.C.F.R. Strawberry-tree, blackthorn and rose fruits: Detailed characterisation in nutrients and phytochemicals with antioxidant properties. Food Chem. 2010, 120, 247-254. [CrossRef]

Sample Availability: A plant voucher specimen is available from the authors.

(C) 2016 by the authors; licensee MDPI, Basel, Switzerland. This article is an open access article distributed under the terms and conditions of the Creative Commons Attribution (CC-BY) license (http://creativecommons.org/licenses/by/4.0/). 